\title{
It Doesn't Rain it Pours-Reflections on Fieldwork in The Academic Year 2019/20
}

\author{
Stephen Holmes ${ }^{1}$ \\ ${ }^{1}$ Royal Holloway University of London| petm010@live.rhul.ac.uk | \\ https://orcid.org/0000-0002-4198-1760
}

\begin{abstract}
The crucial component to any research being successful is fieldwork and gaining access to research participants; which in the academic year 2019-2020 in England became a challenging endeavour, with regards, a) industrial action across the higher education sector, in December 2019 and again in February 2020; b) regional rail network industrial strike action across the year, and c) the pandemic (Coronavirus). This perfect storm restricted and challenged qualitative data collection for a study on 'Teaching Innovation in 21st century UK Higher Education'. Writing from a postgraduate researcher position and perspective who was caught in university halls of residence; this paper reflects a meaningful mental activity and an approach to telling stories. Through my reflections, three themes of experience are significant. 1) Connection and access to participants, Implications of mass media reporting; workloads and screen time. 2) The use of visual method selection is difficult to achieve over a series of digital platforms regarding network failures, functionality, visual descriptions, and feelings of incompetence in understanding the impaired spoken drawing, and 3) the emotional toll on the researcher.
\end{abstract}

Keywords: reflection, lived experience, fieldwork, constraints, and challenges, covid-19.

\section{Introduction}

There is a phrase that bad things happen in threes, a theme that during this inquiry has undoubtedly come to fruition, especially this academic year. The idea behind this phrase is that 'bad' things happen, after which good things follow, seemingly? I cannot share the latter part of the statement as I sit in my magnolia asylum (halls of residence) at the start of the third lockdown regarding the new British variant of the virus. The paper will draw on experiences in the academic year 2019/20 in England, as a postgraduate researcher conducting qualitative research focusing on the views of innovative university instructors in two English research-intensive universities.

The research question $(R Q)$ for this article how the pandemic affected my qualitative inquiry and the emotions this postgraduate researcher has faced? The article will use reflection, an under-used qualitative method, which "allows the reader to explore more freely" (Healey, Matthews, \& Cook-Sather, 2020, p. 194), and as the vehicle to understand the hurdles, challenges, constraints, and directional change that occurred in this period. Boud and colleagues define reflection as "a generic term for those intellectual and affective activities in which individuals engage to explore their experiences in order to lead to a new understanding and appreciation" (Boud, Keogh, \& Walker, 2013, p. 19). The paper embraces Donald Schön's 'reflection-in-action', whereby, the researcher "consciously thinks about what they are doing while they are doing it" (Edwards, 2007, p. 30) in other words thinking on your feet, which was the order of the day back in the initial lockdown. The purpose and aim of this paper are to underpin and embrace problems that are encountered during the fieldwork component, thereby helping others who find themselves in a difficult, unprecedented position. The article contributes to using the rarely used reflective method in bringing about awareness of postgraduate research experiences.

\section{Context}

The context of this paper is aligned with the fieldwork component of my postgraduate research inquiry. Ethics approval was obtained for the main study from the ethics research committee before the main study commenced. The reflections are taken from across my fieldwork notes. My inquiry focuses on exploring the views of innovative university 
instructors in two English research-intensive universities. The research design adopted a draw-talk-talk-draw method of interviewing, which underpins the lived reality of teaching academics, producing an artefact with all its hidden depths of experience. Through markmaking (drawing), one recalls the process of its becoming through the act of mark-making. "When we do not have the words to say something, drawing can define both the real and unreal in visual terms" (Kovats, 2007, p. 8). Pictures, after all, are said to paint a thousand words.

Since commencing research, I have been confronted and challenged by several elements restricting the study's progress. Severe weather in the form of floods and industrial action across the rail network hindered transportation to educational libraries, interviews, and network meetings, making it challenging to recruit volunteers across the study. Academic, industrial action in England fed into the data collection period leading to re-scheduling and participants having to drop out due to other pressing commitments and workloads. However, these few interruptions are a mere nothingness compared to the pandemic of Covid-19 that sent countries and nations into confinement, resulting in an educational crisis never seen before. The fabric of nations across the globe changed, resulting in a new symbolism.

The national symbolism of England has changed over these last few months. The Union flag has been replaced by a spectrum of colour, a blanket of rainbows adorning nearly every window and doorway, chalked on pavements and roads, and even projected on private and national buildings. The national personification has become the gowned, masked health and care workers instead of Britannia. The coat of arms is the NHS, and Care badges and the motto 'Stay at home, Protect the NHS, and Save Lives' has become embedded in our daily lives. The national anthem has been replaced by the clatter of clapping hands and banging of pans, instead of ceremonial drums and trumpets. All of which has symbolised not just our support for health and social work staff on the frontline but also a symbol of solidarity, togetherness, and connection through the difficult times.

Before undertaking the second English research-intensive university in January, I had already completed twenty-five interviews with the first English research-intensive university. This first set of interviews ran exceptionally well with regards to participation and data retrieval. I was able to make appointments and interview on a face-to-face basis, which led to building a better rapport regarding interaction and a deeper participation with the mark-making, or drawings. My original design involved face-to-face interviews with $A 3$ drawing paper and a selection of colored pens; supplied by myself. The interviews were recorded using an encrypted Dictaphone, therefore, catching participants' verbal interpretations of their drawings, hence the term draw-talk-talk-draw. However, the second university did not share the quality that I had got from the first university. However, the second university proved more difficult, in the sense of interview format at the start of the national lockdown. I had to adapt, find a new direction to collecting data, data that would still be usable, encompass some visual theme, or be as near as possible. At that time, I was frustrated, thinking that I would have to lose the data's visual aspect, especially when the images I had already were data-rich, with hidden symbols. Nevertheless, as Celia Brackenridge's (2001) discloses through her fieldwork diaries, there are many "stumbling blocks, changes of direction and breakthroughs" (p. 148) that so often can make a mess of the research process. This paper highlights my stumbling blocks during the lockdown period of early 2020 .

\section{Methodology}

This reflective study follows an interpretivist epistemology; an interpretive search and understanding of oneself during a pandemic while undertaking fieldwork, therefore embracing the researcher as part of the research. It is the researchers' reflection and interpretations that are influential (Brown, 2015), after all, I have actively constructed interpretations of my experiences undertaking fieldwork (Primeau, 2003). Qualitative research is viewed as both "transformative and interactive" regarding pursuing understandings of the lived experiences through interpretations of those experiences 
(Sword, 2016, p. 270). This iterative process can be "messy and unpredictable" (Aspers \& Corte, 2019; Healey et al., 2020, p. 194). The paper uses reflection as the instrument to understand the informal, first-person accounts of undertaking qualitative research in a period of unprecedented interruption during the Coronavirus pandemic. In using reflection, the paper emphasizes the lived experience that portrays the practicalities of researching, both positive and negative. The perspective-taking that reflection offers highlights the researcher's identity and situates the reader in the shoes of another. Perspective-taking centralizes identity and emotions, thereby connecting with feelings (Healey et al., 2020).

Reflection is a practice suspended somewhere around the notion of learning and thinking (Moon, 2004, p. 80), a practice that is both "methods and techniques that help individuals and groups reflect on their experiences and actions" (Plowman, 2015). Reflection is a subjective qualitative research device (Primeau, 2003). A device that in the words of Jenny Moon (2013) implies learning, "reflect in order to learn something, or we learn as a result of reflection" (p. 80). It is through reflection that we "tell our stories" (Yancey, 1998, p. 53). Mills and colleagues, define storytelling as the "ability to shape life events into experience in a web of stories" (Mills, Durepos, \& Wiebe, 2010, p. 2). Other commentators such as Frederick Steier have referred to it as "bending back on itself" (Steier, 1991, p. 2), indicating a process of capturing the lived experience (Healey et al., 2020). The lived experience being "multi-layered and multi-sensorial" (Reavey, 2020, p. 27). The notion of understanding ourselves and our interactions with others (Boodt \& Mos, 1993) in the "lifeworld" (Alfred Schütz's notion of the social world as ordinary individuals live it) (in Harrington, 2006, p. 341).

Reflective practices shape our cognitive processes; it is a significant mental activity, mental activity in the form of "making oneself the object of inquiry" (Mortari, 2015, p. 1). The practice of reflection is self-identification, an awakening of self-consciousness (Cai, 2013), a philosophical stance that frequently refers to reflection as "turning to oneself and examining one's own mental states or acts" (Cai, 2013, p. 341). However, as Moon argues, reflection is a representation, not a "mirror in the head" (Moon, 2004, p. 80).

Reflection is no different to any other methodology it raises ethical concerns regarding confidentiality and anonymity of the issues under reflection. As Vikki Pollard (2008) suggests, "experience is not personally owned but rather a conversation between the self and that which is not-yet known" (p. 399). Within reflection there is a high degree of "emotionality" (Ghaye, 2007) whereby oneself can be subjected to one's own feelings. As Tony Ghaye posits, reflecion should "come with a health warning" (Ghaye, 2007, p. 153). Ethically I have used my own "inner compass and emotional indicator about what might make us feel good or bad", and that great care is taken in understanding the "potential to affect both the writer and the audience is taken into account" Einhorn (2006) in (Ghaye, 2007, p. 155)

\section{Reflection (January 2020-May 2020)}

My study, like any research study, relied on gaining access to innovative instructors. Access, according to Cunliffe and Alcadipani (2016), which is both "problematic and involves working in complex social situations" (p. 535). Gaining access at the best of times can be fraught with difficulties, and I had experienced many, as I call them 'silent sleeping emails', those emails which have zero response and lead to moments of frustration and deep fear that no one wants to know. It makes you feel like you are inquiring about the wrong thing, and whether you are doing something wrong. Therefore, in the midst of a pandemic, it became even more problematic. Problematic because of the need to be "sensitive to what was, is going on around us" (Ann L Cunliffe, 2011, p. 667). I recall the news items and the sharp increase in infected people and families who have been torn apart after losing relatives and friends. The emotional toll on myself as the researcher became apparent when composing emails and staring at the send button, knowing that I could be emailing individuals who have experienced loss. That is not to say that even before the pandemic that the element of loss was not present, it is just that it was exacerbated by what was unfolding in front of my eyes. I remember thinking is this worth 
it, especially when media outlets were reporting the impending doom of higher education. You also compartmentalize, prioritizing one's life through events, such as that of the pandemic, trying to capture that tiniest ounce of directional drive, the resilience to reengage. To recognize the "concreteness of everyday being-in-the-world" (Barnacle, 2004, p. 66). The soul searching that goes on when you are in what I would call a 'static alternative dimension', which underpins this tearing of the fabric of your lifeworld, resulting in stopping you in your tracks seems to play heavily upon the mind. Therefore, I had to place things in perspective, yes things are terrible, but, and I capitalize but for a reason. It is not forever, the work you are doing will hopefully help change someone's outlook on teaching, and most of all, the need for oneself to thrive and become successful, need to drive your thoughts. The initial quote in the introduction 'bad' things do happen, but they are only a short, small part of your overall story.

\subsection{Method Adoption}

With lockdown firmly in place and time ticking away regarding fieldwork, I needed to diversify concerning the collection of data for my central inquiry. I found myself searching for new ways to undertake the interviews. Well, new to me because I had never used digital means to undertake interviews before, even though such applications, "digital devices and data have offered new possibilities for social research" (Gangneux, 2019, p. 1249; Lo lacono, Symonds, \& Brown, 2016) for some time. I knew I would lose some of the productive interactions of the visual lived experience (drawings), and in some cases, this was true. I had to turn to the visual description. Participants described their images to me, resulting in a verbalized visual artefact, which worked insofar to visualize a kind of image but found it challenging to explore the hidden visual symbols. However, I had data I could work with, which would embrace the research questions, albeit not visually in-depth. In times like this, one has to adopt the position that any data that is useable in your inquiry is better than none.

Alternatives to face-to-face interviews were easily identified, especially nowadays, where mobile hand-held smart devices and computer terminals now have standard audio and video capabilities (Hooley, Wellens, \& Marriott, 2012). Sullivan (2012) proposes that "the potential for video conferencing as a research tool is almost unlimited" (p. 60). There were positives to moving my interviews online and connect collaboratively; firstly, it alleviates some of the conventional face-to-face interview challenges, such as, 'overcoming time zones and monetary constraints, geographical dispersion, and physical mobility boundaries' (Janghorban, Roudsari, \& Taghipour, 2014, p. 1).

Many platforms now exist (Google Hangouts, Apple FaceTime, Skype, Zoom, Webex, Goto, Microsoft Teams and Houseparty (Null, 2020), to name but a few. Interestingly, many of the key players in social media have now developed real-time audio-visual collaboration, or groupware, where collaborations can be undertaken irrespective of distance. There seems to have been and still is a race to produce the ultimate functionality among a prominent group of developers. A race that seems to have been started by Zoom, an application that soon characterised universities with the wordplay of 'zoomiversity'.

I needed to offer as much flexibility as I could in-order that participants had a choice in platform. The platforms or applications I chose involved email, telephone, Zoom, Skype. At this point, I had settled for verbal visual descriptions because I wanted to complete my data collection and because I had not realized the functionality of the platforms and was not a competent social media or videoconference person. Thinking back now, one could have asked them to use any spare paper they had and screenshotted them after completion or using drawing tools on the screen. So where is my advice here, well, I am not sure whether there is? I could have learnt more and practiced more with colleagues about the platforms' workings. I could have researched more about the platforms, but time and the pandemic, followed with isolation, seemed to hasten a quick resolve. In other words, get the data. The platforms all had their unique characteristics and challenges, which we will turn to next. 


\subsection{Email Images}

The use of emails as an instrument for data collection was not very successful, especially using images as a driver into the world of experience. This method meant that I had to send the questions via an attachment, similar to sending a questionnaire. Two participants utilised the method. The method did have some descriptions, and the replies had usable data. However, the image was lost with this method. Through this method, I found that the researcher has no control, and by control, I mean being able to probe. The email method takes away any interaction between both researcher and researched. I have looked back at the use of emails as a method, and I believe emails would not produce the probing that goes on when discussing images. The searching for the hidden is too far away, and distance when using images is, as I have found, disappointing.

\subsection{Telephone Images}

I offered telephone calls because this would be easier. After all, most people now own a mobile phone. The telephone conversations worked well, and I was able to gain a spoken image. Four participants used the method because it was more convenient. I asked the participants the questions, and at the same time, I also drew the conversations. This meant returning to the image I was drawing to check and clarify that this is what they would have drawn. Yes, the perspective was not their own, and yes, the image was drawn by me, but the participants' visual image of the question was ever present. A problem with this method I found was that the interviews were extended with regards time. All interviews were onehour long, but the telephone ones sometimes ran over that, this was something that I had prepared for and mentioned in my introductory emails to participants. So, what is the takehome from using mobile telecommunications for interviews with images? Firstly, factor in time, make sure you are in a quiet place regarding Dictaphone recording of the conversations and have enough desktop space top draw. Above all, tell the participants the drawing materials you are using, size, colored pens, etc. Participants need to choose the color, orientation, and where to start, clarify the drawing, and be mindful of time.

\subsection{Videoconference applications}

The reflections below focus on the videoconferencing applications, Skype and Zoom, which I employed during the specific period. I chose Skype because it was free and because I was familiar with its functions; most people have also used Skype because it has been around for several years (Janghorban et al., 2014). Zoom, on the other hand, was founded in 2011 by Zoom Video Communications and has become the latest and perhaps the most used videoconferencing platform, with "seven in ten people making video calls at least once a week during the lockdown, with millions turning to Zoom for the first time" (BBC News, 2020). However, Zoom has had several teething issues regarding some severe security flaws (now fixed). The Guardian reported in April 2020 that Zoom had a '535\% rise in daily traffic' and that security experts had relayed their concerns that Zoom was a 'privacy disaster' and 'fundamentally corrupt' (Paul, 2020a, 2020b). Cases of video hijacking or Zoom-bombing were on the increase, which meant that other people could hack into your meeting. End to end encryption had not been adopted. Nevertheless, Zoom did address the security issues (Paul, 2020b).

The use of Zoom as a videoconferencing tool did not sit well with me during the early part of this year due to the security issues, as mentioned above, and although the rest of the country, or as it seemed to me was championing the platform, irrespective of its malware tag ("any software intentionally designed to cause damage to a computer, server, client, or computer network") (Microsoft, 2009). I was unsure whether to use the platform because of ethical issues, unsecured data collection. To be honest, I did not add the platform to the email invitation until I had spoken to Information Technology (IT) experts and researched further into Zoom's solution to its security problems, even though the UK Government were using it for their cabinet meetings. My change of mind came when I had read that Zoom 
had fixed the end-to-end encryption problem (Paul, 2020b) and that I had further researched the platform's functionality, making me confident with making all meetings' private meetings' (Zoom, 2020).

\subsection{Problems Encountered}

Qualitative interviews generate elaborate portrayals of individuals' lives and authentic lived reality. They record real persons in their context or life-worlds revealing meanings. The researcher and researched construct a relationship and establish a rapport through combined verbal and nonverbal narrative and experiences (Weiss, 2010). Both Skype and Zoom both offer some of those experiences like face-to-face interviewing if connections are not fractured. One of the main problems during the lockdown has been maintaining a stable network connection; something reverberated through the mass media (Wakefield, 2020). With millions of people working remotely at home during the lockdown, the network has experienced troughs and peaks, especially at the researcher's location. This has led to frequent drops in connection, which of course is out of one's control.

Some issues that audio-video conferencing applications have are their susceptibility to weak online connections, especially across continents which I have found (Deakin \& Wakefield, 2014). Although the interview can be undertaken in ones, own personal environment and at one's convenience and comfort (Deakin and Wakefield, 2014), there still needs to be a stable connection. Some conference platform calls are synonymous with unforeseen disconnection or unintended pauses that can be extremely embarrassing when your synthetic portrait is distorted. This can lead to either the participant or the researcher missing large parts of conversations. A standard account in of this study has involved participants saying, "where did we get to," "I just kept talking because I thought you could hear me," or "I wondered where you had gone, I was talking to myself," leading to some frustration but an understanding of the platform. Another issue was the sound quality, which hindered the interviews and the transcription of the interviews.

Sound quality varies immensely, like that of the visual video image; it all depends on the hardware's quality in which you have inbuilt into one's computer or smart device. Webcams and sound cards are vital to having a productive high-quality online interview experience, both of which the researcher has. However, like the disconnection and pauses above, sound can be just as unstable. In some interviews, I experienced background interference (household noise, external traffic), participant, and researcher movement, which in some cases triggered a muting of the microphones. The video feed glitches meant that the sound became synthesized and challenging to understand, recalling some thoughts of Dr Who's Daleks.

\section{Conclusions}

This paper has used the underused used methodology of reflection, or as I would like to call it, a conversation with oneself. The RQ for this article was how the pandemic affected my qualitative inquiry and the emotions one postgraduate researcher has faced? This article aimed to shine a light on some of the difficulties encountered as I undertook my fieldwork using a draw-talk-talk-draw method style of interviewing during the Coronavirus pandemic, a method that emphasises participation, interaction.

Reflection is an essential element in research; it allows individuals the chance to pause, to engage in meaningful, thoughtful connections with the lifeworld they reside. Reflection highlights the need to 'dig out' (Mortari, 2015) and gain awareness of our experience; therefore, learning from experiences. My encounters with reflection have given me a greater understanding of the complexity of reflection. Reflection has demonstrated in this paper the need to learn from unfolding developments, with regards the pandemic.

In summary, it is very easy to take for granted the simplest of tasks. The pandemic highlighted the importance of interaction; after all, we are all social beings and the stress and tensions one experiences due to uncertainty and an unwillingness to adopt new 
approaches. For me, like others in the educational sector, the pandemic has lifted the lid on how much we actually enjoy each other's physical presence. The numbers of teachers I know and that have broadcast their views on the present situation have emphasised the human aspect of education over the digital synthetic aspect of education. This research uncovered three themes.

The connection and access to participants only became difficult because of the mass media reporting. The pandemic made you think more deeply about your role as a researcher and the ethical consideration that are paramount in research. The media coverage altered one's perceptions of what was essential, and the directional travel I was going in. Would there be any jobs at the end of this, especially when you are on the wrong side of 50 , will higher education change out of all recognition. The second theme concluded that visual method selection is difficult to achieve over a series of digital platforms regarding functionality, visual descriptions, and feelings of incompetence in understanding the impaired spoken drawing with regards to technological malfunctions. However, as implied above, when you are thinking on your feet, you can make mistakes and one's own competence regarding technology functionality can be extremely distant. The third and final theme was possibly the most difficult, the emotional toll on the researcher. My only conclusion to this theme is that the period has been a roller coaster, with more deep plunges than climbs. Emotionally isolation and motivation are not the best two concepts to be working in while undertaking postgraduate research.

\section{Limitations of Reflection}

Reflection as a method has limitations. This article which is not exhaustive with regards to my fieldwork experiences only captures fragments of the experiences. Therefore, obscuring relevant occurrences related to the situation and rejecting the entirety (Mortari, 2015). Reflection is limited to informal, first-person accounts because it embraces the individual and their specific lens and therefore is subjective. Healey and colleagues suggest "that reflection neither marshals evidence to prove something nor strives to convince anyone of anything in particular" (p. 198).

\section{Acknowledgements}

Many thanks to all those outstanding, hard-working academics who participated in my main study.

\section{References}

Aspers, P., \& Corte, U. (2019). What is qualitative in qualitative research. Qualitative Sociology, 42(2), 139-160. https://doi.org/10.1007/s11133-019-9413-7

Barnacle, R. (2004). Reflection on lived experience in educational research. Educational Philosophy and Theory, 36(1), 57-67. https://doi.org/10.1111/j.1469-5812.2004.00048.x

BBC News. (2020, June). UK's internet use surges to new highs during lockdown. https://www.bbc.co.uk/news/technology-53149268

Boodt, C. P., \& Mos, L. P. (1993). Hermeneutics of lived experience: The foundations of a historical psychology. In H. J. Stam, L. P. Mos, W. Thorngate, \& B. Kaplan (Eds.), Recent trends in theoretical psychology (pp. 111-122). Springer. https://doi.org/10.1007/978-1-4612-27465_10

Boud, D., Keogh, R., \& Walker, D. (2013). Reflection: Turning experience into learning. Routledge.

Brown, N. (2015, December). Epistemology. https://www.nicolebrown.co.uk/epistemology/\#: :text=Interpretivism\%3A, and\%20removed\%20from\%20the\%20r esearch. 
Cai, W. (2013). Reflection and text: Revisiting the relation between pre-reflective and reflective experience. Human Studies, 36(3), 339-355. https://doi.org/10.1007/s10746-013-9287-8

Cunliffe, A. L. (2011). Crafting qualitative research: Morgan and Smircich 30 years on. Organizational Research Methods, 14(4), 647-673. https://doi.org/10.1177/1094428110373658

Cunliffe, A. L., \& Alcadipani, R. (2016). The politics of access in fieldwork: Immersion, backstage dramas, and deception. Organizational Research Methods, 19(4), 535-561. https://doi.org/10.1177/1094428116639134

Deakin, H., \& Wakefield, K. (2014). Skype interviewing: Reflections of two PhD researchers. Qualitative Research, 14(5), 603-616. https://doi,org/10.1177/1468794113488126

Edwards, J.-A. (2007). Primary trainees' reflection-in-action. Proceedings of the British Society for Research into Learning Mathematics, 27(1), 30-35. https://dera.ioe.ac.uk/13033/1/5469.pdf

Gangneux, J. (2019). Rethinking social media for qualitative research: The use of Facebook Activity Logs and Search History in interview settings. The Sociological Review, 67(6), 1249-1264. https://doi.org/10.1177/0038026119859742

Ghaye, T. (2007). Is reflective practice ethical? (The case of the reflective portfolio). Reflective Practice, 8(2), 151-162. https://doi.org/10.1080/14623940701288859

Harrington, A. (2006). Lifeworld. Theory, Culture \& Society, 23(2-3), 341-343. https://doi.org/10.1177/026327640602300259

Healey, M., Matthews, K., \& Cook-Sather, A. (2020). Writing about learning and teaching in higher education. Elon University Press. https://doi.org/10.36284/celelon.oa3

Hooley, T., Wellens, J., \& Marriott, J. (2012). What is online research?: Using the internet for social science research. Bloomsbury Publishing.

Janghorban, R., Roudsari, R. L., \& Taghipour, A. (2014). Skype interviewing: The new generation of online synchronous interview in qualitative research. International Journal of Qualitative Studies on Health and Well-being, 9(1), 1-3 https://doi.org/10.3402/qhw.v9.24152

Kovats, T. (2007). The drawing book-a survey of drawing: The primary means of expression. Black Dog Publishing.

Lo lacono, V., Symonds, P., \& Brown, D. (2016). Skype as a tool for qualitative research interviews. Sociological Research Online, 12(2), 1-15. https://doi.org/10.5153/sro.3952

Microsoft. (2009). Defining malware: FAQ. https://docs.microsoft.com/en-us/previous-versions/tnarchive/dd632948(v=technet.10)?redirectedfrom=MSDN

Mills, A. J., Durepos, G., \& Wiebe, E. (2010). Storytelling. In A.J. Mills, G. Durepos, \& E. Wiebe (Eds.), Encyclopedia of Case Study Research (Vol. 1, pp.896-898). https://doi.org/10.4135/9781412957397

Moon, J. (2004). Reflection in learning and professional development: Theory and practice. Routledge. https://doi.org/10.4324/9780203822296

Mortari, L. (2015). Reflectivity in research practice: An overview of different perspectives. International Journal of Qualitative Methods, 14(5), 1-9. https://doi.org/10.1177/1609406915618045

Null, C. (2020). 6 popular videoconferencing tools compared. https://www.wired.com/story/6 popular-video-conferencing-tools-compared-zoom-skype-houseparty/

Paul, K. (2020a, April 2). Zoom is malware': why experts worry about the video conferencing platform. The Guardian. https://www.theguardian.com/technology/2020/apr/02/zoomtechnology-security-coronavirus-video-conferencing

Paul, K. (2020b, April 23). Zoom releases security updates in response to 'Zoom-bombings'. The Guardian. https://www.theguardian.com/technology/2020/apr/23/zoom-update-securityencryption-bombing

Plowman, P. (2015). Reflective practice. Participatory Methods. https://www.participatorymethods.org/method/reflectivepractice\#: :text=Methods\%20from\%20research\%20and\%20other,and\%20integral\%20to\%20t heir\%20analysis. 
Pollard, V. (2008). Ethics and reflective practice: Continuing the conversation. Reflective Practice, 9(4), 399-407. https://doi.org/10.1080/14623940802431788

Primeau, L. A. (2003). Reflections on self in qualitative research: Stories of family. American Journal of Occupational Therapy, 57(1), 9-16. https://doi.org/10.5014/ajot.57.1.9

Reavey, P. (2020). A handbook of visual methods in psychology: Using and interpreting images in qualitative research. Routledge.

Steier, F. (1991). Research and reflexivity. Sage.

Sullivan, J. R. (2012). Skype: An appropriate method of data collection for qualitative interviews? The Hilltop Review, 6(1), 54-60. https://core.ac.uk/download/pdf/144151682.pdf

Sword, W. (2016). Accounting for presence of self: Reflections on doing qualitative research. Qualitative health research, 9(2), 270-278. https://doi.org/10.1177/104973299129121839

Wakefield, J. (2020). Coronavirus: Coping with lockdown on poor broadband. BBC News. https://www.bbc.co.uk/news/technology-52414280

Weiss, R. S. (2010). Learning from strangers: the art and method of qualitative interview studies. New York: Free.

Yancey, K. B. (1998). Reflection in the writing classroom. Utah State University Press

Zoom. (2020). Zoom rooms private meetings. https://support.zoom.us/hc/enus/articles/115001051063-Zoom-Rooms-Private-Meetings 